\title{
Evaluation of Factors Influential on Increased Social Participation in Unofficial Residences in Big Cities (Case Study: City of Tabriz)
}

\author{
Samad Shahnahad \\ PhD Population Sociology, Baku Public University; samad_shahnehad@yahoo.com \\ Habibollah Zanjani \\ Associate Professor of Tehran University
}

Doi:10.5901/mjss.2016.v7n2s2p215

\begin{abstract}
For their development, cities need multilateral participation of citizens and those profiting from city facilities. Since emigrants reside in unofficial residential sites, due to lack of formal recognition in the city domain, they are not considered as citizens and providing them with facilities is a difficult task. Identification of factors effective on their level of participation can be tremendously helpful in city development and organization and enablement of unofficial residential sites. Informal housing is a well known matter as a problem in cities and has numerous negative consequences such as economic, cultural, security, environmental and corporal issues for cities and as a result, emigrants and city officials encounter significant difficulties and large expenses. The purpose of this research is identification of factors influential on the level of social participation of emigrants residing in unofficial residential sites in big cities. The mentioned phenomenon is mostly observed in developing countries. By virtue of this matter, the city of Tabriz which is one of the big cities in Iran and near 25 percent of its population live in unofficial residential sites was selected as sample. Results show that identification of participation enhancing factors and factors influential on participation will tremendously help in accompanying people in various social problems.
\end{abstract}

Keywords: Unofficial Residential Sites, Social Participation, Social Awareness, City of Tabriz

\section{Introduction}

The history of human livelihood is a history of collaboration and participation. The time that humans for the first time became aware that they can overcome problems by putting together their forces, the meaning of participation was born. The Democracy in Athens was a reflection of the wishes of citizens to determine their own destiny. From collection of human historical experience, participation arose in its today meaning. Now a day, participation in the context of a democratic and civil society has an established form to it. In a civil society, collaborations independent of the government provide the context for participation of individuals in matters pertaining to them under equal conditions and with possession of equal information and facilities.

\section{Statement of the Issue}

With growth of city dwell ship due to various reasons including industrialization and creation of technologic tools and increased facilities and city attractions as well as changes in village communities and small cities, emigration has found a more rapid trend and occurs at higher levels and as a result, emigrants rush toward cities. Considering the lack of adaptive conditions and capabilities of emigrants and lack of city accommodating capacity, a significant portion of these emigrants have not had the opportunity to be present in the official and legal sectors of the city and have resided in the unofficial section. Lack of appropriate facilities for living in these areas, undesirable appearance, low levels of public health and healthiness, lack of official occupations and sufficient income, population density, inappropriateness of educational and well fare facilities and low levels of literacy and education, addiction, social deviation and diversions and etc, tremendous expenses have been forced upon the city and development has been barred. One of the most important factors for enduring development is voluntary participation of people in management of matters. For development, cities need multilateral participation of citizens and benefactors of city facilities. Considering this issue that emigrants reside in unofficial residential sites, due to not being formally recognized in the city domain, they are not considered as citizens and provision of facilities for them is a difficult task. Identification of influential factors on their level of participation can 
significantly help in the development of the city of Tabriz and organization and enablement of unofficial residential sites.

\section{The Importance and Necessity of Consideration of this Topic}

Regarding usefulness of immigration to cities or not, different and various views have been proposed. Yet, agreement exists regarding emigration ending in unofficial residential situations (outskirt inhabitation) and city development facing disruption and irreversible damages.

Unofficial housing is a well known city complication and has numerous negative consequences such as economic, cultural, security, environmental and corporal problems for cities and emigrants and city officials are faced with tremendous issues and are forced into great expenditures and it is considered as a barrier to developmental progress. Disconsidering emigrants in unofficial residential sites and considering their presence in various city areas and effective connection with the city enforces huge expenditures for the city and citizens and the inhabitants themselves as well. To the same extent that their lack of participation and responsibility in city matters challenges city development, their participation can pave the path of development and hasten it (Monzavi, 1998). The importance of participation can be stated such that participation is the path to breaking dependence, exiting from staying behind, defeating underdevelopment, discovering regional capacities and relying on internal resources and forces in the process of development (Rafipour, 1993: p35).

\section{Research Purposes}

- Identification of the situation of social participation of emigrants residing in unofficial sites of the city of Tabriz (Iran)

- Identification of influential factors on the level of social participation of emigrants residing in unofficial residential sites

- Evaluation of the level of social participation of emigrants residing in unofficial sites

\section{Main Question}

What are the influential factors on the level of participation of the emigrants residing in unofficial residential areas?

\section{Hypotheses}

- Meaningful correlation exists between the level of awareness of emigrants residing in unofficial sites and their social participation.

- Meaningful correlation exists between the feeling of partial exclusion by emigrants living in unofficial residential sites and the level of their social participation.

- Meaningful correlation exists between the level of cultural acceptance by emigrants living in unofficial residences and their level of social participation.

- Meaningful correlation exists between the feeling of belonging to the city of emigrants living in unofficial residences and their level of social participation.

- Meaningful correlation exists between the time of presence of emigrants in unofficial residence sites and their level of social participation.

Statistical Population: Statistical population includes emigrants living in unofficial sites in the city of Tabriz and the total population of outskirts of the city of Tabriz is near 400 thousand people.

Sampling Method: Sampling was performed by combined stratified, quota and simple randomization.

Estimation of Sample Size: Sample size estimation was performed using the Morgan table according to which for a statistical population of 400 thousand people, 400 individuals are identified which constituted the statistical sample size. Sampling was performed in each area relative to its population and individuals from different age ranges and genders were participants in the study.

Definition of Key Concepts and Variables:

Outskirt Inhabitance: «outskirt inhabitance» is a phenomenon on the basis of which a group of people living in the city perimeter have not become absorbed into the social and economic system of the city (Zahed Zahedani, 1990: p29).

In the writings of Robert Park and Stone Quist also the concept of outskirt inhabitance has been attended to and evaluated. These two researchers endeavored to explain the arising of a kind of personality, namely the outskirt 
inhabitant particularly cases in which cultures interact and contradict each other. According to the theory of Park: the outskirt inhabitant is an individual that destiny has committed him into living in two societies and two cultures not only different, but also in hostility.

Stone Quist in adherence to Park emphasizes on psychological outskirt inhabitance resulting from «cultural altercation and discriminatory simulation». In the opinion of Stone Quist, the outskirt inhabitant or «marginal man» is an individual that leaves a socio-cultural group by emigration, education, marriage or other effective matters without satisfactory attachment to another group and finds him or herself in the outskirts of that group without being a member of either of them. This individual becomes an outskirt inhabitant when he or she considers the problems of the group as his or her own personal problem.

Park and Stone Quist look positively at the outskirt inhabitant and in him they see the possibility for advancement and progress. Park believes that with analysis of the

thoughts of the outskirt individual, we can in the best way study the method of civilization and progress. Similarly, Stone Quist emphasizes that it is in the mind and thoughts of the outskirt individual where cultures interconnect and face each other and eventually lead to the output of a common product. Such individual is the melting pot and interacting place of rivaling cultures.

Awareness: Daniel Lerner defines awareness as follows: one of the factors for social dynamicism is people's awareness regarding rights, duties and finding the main reasons for social problems such that the relationships and interactions present in society can be evaluated and by correctly analyzing them and reaching deep and essential perception of social foundations, functional and mental capacity can be increased.

The Feeling of Relative Exclusion: Ted Garr states that what is meant by relative exclusion is the mental picture of the difference between value expectations of interactors and appearing value capacities in their environment. Garr refers to three kinds of exclusion: 1) decremental exclusion or exclusion due to decline: relative stability of value expectations and decline of value capacities; 2) exclusion resulting from growth of demands: relative static nature of capacities and strong increase in expectations; and 3) incremental exclusion: fundamental and concurrent increase in expectations and decrease in abilities. In his opinion these three kinds of exclusion can be the causal or contextual factors in aggression (Moshirzadeh, 2002: p129).

Acceptance of Culture: Acceptance of culture means acquisition of material and nonmaterial qualities of another society and culture. In other words, acceptance of culture refers to the cultural transformation that occurs by virtue of expansive and direct contact between two or multiple groups which were independent groups prior to this contact.

Participation: Allen Bayrou defines participation as follows: «participation means having a share in something and profiting from it or getting involved with a group and therefore collaborating with it. For this reason, from a sociologic point of view, there is need for differentiation between participation as a situation (the matter of participation) and participation as an action or commitment (action of participation). In the former meaning, participation informs us of belonging to a special group and having a share in its existence and in the latter meaning is active involvement in the group and refers to the social activity performed» (Bayrou, 1996: p257).

In the opinion of some researchers, participation is a developing concept and is accompanied with transfer of power (Lowe et al, 1999: 14-17) and is a form of intrinsic development that occurs in time in response to the two questions of why and how and includes the meaning of provision of regional resources and support of internal data inside programs for creation of higher functioning (Lowe et al, 1999: 12).

The World Bank defines participation as a process in which benefactor groups intervene and supervise over guiding the direction of developmental innovations and decision makings and resources that are effective in life.

The United Nations provides a similar definition of the process of participation and refers to it as a tool: «participation is a tool for increasing the opportunity for presence of people in the process of decision making in a way that they benefit from their activities. " Additionally, in the view of the development plan of the United Nations, participation is a tool for growth of social awareness and encouragement of pioneering in regional activities such that the structure of regional decision making needs to encourage and support intervention of the natives in issues directly related to their needs.

\section{Different Kinds of Participation}

Due to conceptual expansiveness and kind of application in various sciences and different dimensions, participation has various kinds: 


\subsection{Classification of participation based on the level of role of individuals}

Based on the level of role of individuals, participation is divided into two groups:

A-1) Fundamental participation (multi dimensional): fundamental participation refers to multilateral, voluntary, aware, bilateral based on interests, needs, mutual confidence and relatively complete by all social groups without attention to gender, race and ...

A-2) Marginal participation (one dimensional): one dimensional participation usually occurs for implementation of programs with special purposes and determined from before. Participation in capital provision for building of a school by people is a kind of unilateral participation. In this kind of participation, when financial help is provided, the job is considered finished in the view point of participation and the participator.

\subsection{Classification of participation based on implementation and planning levels}

On this basis, participation is divided into four classes:

B-1) Local (villager) participation: is a kind of participation the purpose of which is stimulation and motivation of villagers particularly vulnerable groups in plans and programs for development and progress of their residential site.

B-2) Regional participation: is the congregational participation of individuals from multiple areas for improvement and betterment of their economic, social and other situation in their region of inhabitance.

B-3) National participation: is provision of necessary contexts for attraction and participation of society's individuals in societies, political, social, economic and cultural institutions.

B-4) International participation: is participation of various societies (without consideration of conditions and characteristics such as race, color, gender and ...) in all plans and activities that pertain to the international level and beyond geographic boundaries. The modern international economic system, protection of human rights is among examples of international participation (Ghasemi, 2001: p30).

\subsection{Classification of participation based on topic}

C-1) Economic participation: is the capability and participation of individuals in any economic activity freely, increased possibility of access to production resources, supervision over the method of management of economic institutes and their profits and losses in the way of decreasing economic inequality (Tousi cited in Ghasemi, 2001: p28).

Economic participation involves creation of rules by which compulsory establishments are obliterated and as much as possible the conditions of freedom and activity for the public participating in economic activities is provided for (Efati, 1999).

Economic participation is the involvement and intervention of most people in relevant decision makings related to allocation of society's resources (Mardoukhi, 1994)

Ultimately, in another place, social participation is the collaborative endeavor of two or more individuals for material profit which is generally specified with an index such as profitability (Peyran, 1988).

C-2) Cultural participation: refers to a kind of participation in which the general public are summoned to participation in creation of culture and advancement of the culture of groups. Strengthening of humane art and facilitation of relationship between cultures in multicultural societies, increase of social agreement in mutli ethnicity communities are examples of cultural participation (Peyran, 1988).

C-3) Social participation: refers to voluntary participation of individuals in social activities. In other words, it refers to creation of equal and similar conditions for participation and presence of all social groups in determination of their destiny (Efati, 1999: p 38).

C-4) Political participation: refers to the group of willful activities by which the members of a community have role in selection of their leaders and directly or indirectly in formulation of societal policies and where entrance into the domain of political power is free for all people at all levels.

Table 1: Variety, source, membership kind and functions of social participation (Taleb, 2000; p13)

\begin{tabular}{|l|l|l|l|}
\hline $\begin{array}{l}\text { Variety of } \\
\text { participation }\end{array}$ & Source of formation of the participatory group & $\begin{array}{l}\text { Kind of membership in } \\
\text { the participatory group }\end{array}$ & Group social functions \\
\hline Natural & $\begin{array}{l}\text { Has traditional source, traditional groups, occupational groups, } \\
\text { family and clan groups... }\end{array}$ & $\begin{array}{l}\text { Naturally and } \\
\text { involuntarily }\end{array}$ & $\begin{array}{l}\text { Strengthening and establishing } \\
\text { traditions, existing traditions and } \\
\text { norms... }\end{array}$ \\
\hline
\end{tabular}




\begin{tabular}{|l|l|l|l|}
\hline Voluntary & $\begin{array}{l}\text { By participatory groups and without influence of factors } \\
\text { external to the group, the group personally organizes its } \\
\text { activities. Guild societies, cooperatives, political groups and ... }\end{array}$ & Willfully and voluntarily & $\begin{array}{l}\text { Provision of new needs, facing } \\
\text { environmental limitations, creation of } \\
\text { new behaviors, adaptation with social } \\
\text { changes, provision of the conditions for } \\
\text { persistence of the evolutions }\end{array}$ \\
\hline Involuntary & $\begin{array}{l}\text { The participatory group is formed by individuals themselves, } \\
\text { new neighboring groups, voluntary traveling companion, } \\
\text { looters, ... }\end{array}$ & $\begin{array}{l}\text { Completely Willfully and } \\
\text { voluntarily }\end{array}$ & $\begin{array}{l}\text { Without visible social functioning, } \\
\text { holding a role in provision of hidden } \\
\text { psychological needs of participants }\end{array}$ \\
\hline Compulsory & $\begin{array}{l}\text { Group formation with intervention of officials outside the group, } \\
\text { development officials, nongovernmental organizations and ... }\end{array}$ & $\begin{array}{l}\text { Influenced by various } \\
\text { motivators }\end{array}$ & $\begin{array}{l}\text { Functioning is social changes, by way } \\
\text { of establishment of a behavior desired } \\
\text { burpos development officials, intrinsic }\end{array}$ \\
\hline $\begin{array}{l}\text { exploiting individuals for completion of projects or formation of } \\
\text { irrigation groups and .... }\end{array}$ & $\begin{array}{l}\text { Compulsory and urgent } \\
\text { fompunctioning and with establishment of } \\
\text { criteria and rules }\end{array}$ \\
\hline
\end{tabular}

Source: Taleb 1910

\section{Theoretical Framework}

Numerous theories exist regarding the reasons and contexts created for participation of individuals and the feeling of social belonging of citizens on the one hand and their feeling of lack of desire and social indifference on the other hand each of which evaluate the issue from a special angle and emphasize various factors. These theories can be divided into four groups:

1- Psychosocial theories

2- Sociological theories (structuralists, functionalists, followers of the conflict theory)

3- Political theories (political renovation)

4- Economic theories

\section{Psychosocial Theories}

Inkeles in his vast studies found out that the lack of success of many countries and societies in developmental achievement is in lack of presence or preparation of individual capacities of people of those societies regarding view points, values, and gravitating predilections for development. In this regard, he states: «realization of a modern society requires presence of citizens that are participatory, interested in public matters, aware of rights and duties outside particular familial and geographic frameworks» (Inkeles, 1994, 5).

\section{Sociological Theories}

Each of the major sociological schools based on their offerings and with attention to the importance of the topic in explaining social participation has been presented:

\subsection{Structuralist approach}

Based on the teachings of this school, people are part of the social structure of every society. People's participation protects societal structures and provides for their sustenance and persistence. What leads to low levels of participation by people in matters relevant to their lives are society's structures that act as barriers in the path of participation. Achieving higher levels of development and better lives requires increased participation of public and formation of necessary structural changes in some political and social constructs.

\subsection{Functionalistic approach}

The approach of this view point towards the topic of participation is attention to roles and functions that are created by participation of individuals and social groups in society. Therefore, participation has positive functionality and guarantees social integration and collect agreement. 


\subsection{Conflict theory approach}

Followers of this approach consider people connected with social class relationships, unequal transaction and conflict and incongruence in interests between different social groups. In their opinion, real participation can be found only in a utopian society without classes.

\subsection{Cultural theory approach}

In the view point of this group, the level of participation of citizens can be evaluated based on creation of changes in norms, stances and collection of values that prevent or encourage social participation.

\section{Political Theories}

In this view point, concentration of political power and its allocation to particular individuals or stratifications and in fact, the closed political system's blockage of the path of entrenchment and power of groups, classes, religions and ethnic minorities in reaching scarce resources of power are among major obstacles in increasing citizen participation. Overall, political concentration leads to decline in the political role of parties, groups and humane societies and decreases interest in socio-political participation by the people. Lack of collaboration and participation of the intellectuals, students and elite groups leads to decrease in political awareness and knowledge in society and ultimately acts as a prohibitor in people's social participation and as a result multilateral activity in society.

\section{Economic Theories}

These theories consider participation the consequence of the evaluation of individuals of the level of advantage and disadvantages resulting from their participation or lack of it in social and political arenas.

Subsets of this classification have been designed regarding participation and acceptance of participation a number of which will be presented.

Berton (1997) believes that among factors influential on social participation, two are particularly valuable; personal characteristics and structural opportunities. Part of participation is explained by factors such as literacy level, individual's social class, religious interests and personal motivations and the opportunity for participation also determines the level of participation because it is different for individuals belonging to various groups.

Arnstein considers participation the sharing of power by the people for influence on the behavior of the government. In his opinion, participation is reallocation of power that occurs at various levels. Arnstein differentiates and demonstrates eight level of citizen participation on a ladder named «Arnstein's participation ladder».

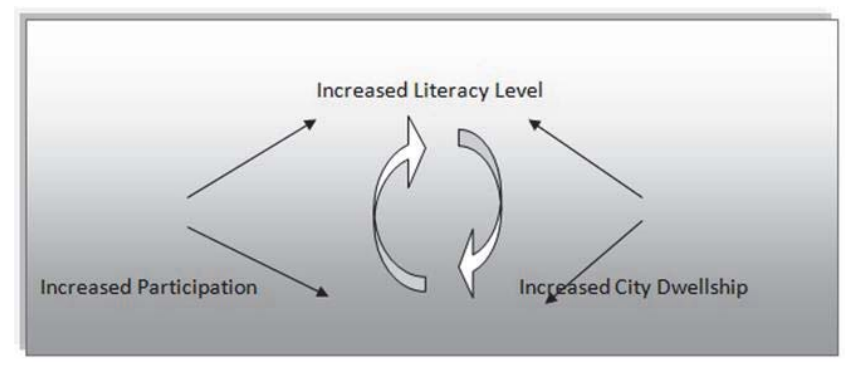

The steps of Arnstein's ladder consist of the following sections:

Citizen control 2.Power exchanges 3.Participation 4.Alleviation 5.Counseling 6.Informing 7.Treating 8.Manipulation and pretensciousness. (Arnstein, 2000, 210-215)

\subsection{Learner's Renovation Theory}

One of the most famous preliminary studies regarding renovation was performed by Daniel Lerner, 1958. In the book "Passage through traditional society," he evaluates the process of renovation in multiple Middle Eastern countries such 
that he performed an example study in developing countries.

In his opinion with creation of psychological stimulation, one can achieve formation of dynamic and active personalities with the power of adaptation and innovation. In his studies, he found meaningful and close correlation between the variables of city dwell ship, literacy, participation and access to media.

In his opinion, renovation is dependent and connected with these 4 variables. In the opinion of Lerner, society's evolution to a participitative society is the organized consequence of change in three aspects:

1- Increased city dwell ship;

2- Which leads to advancement of literacy;

3- which consequently increases access to media;

\section{Research Functional Model}

\subsection{Conclusion and Analysis of Descriptive and Inferential Findings in Response to the Research Questions:}

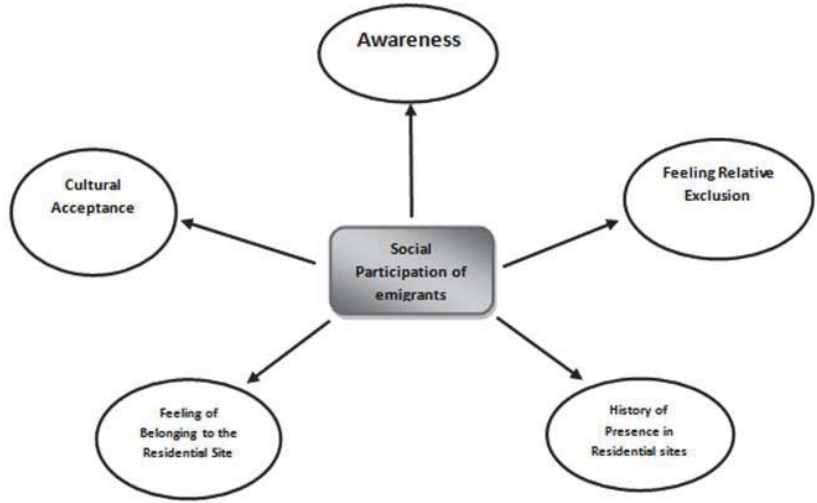

Expansive participation of people is among lawful rights of life and major necessities for realization of the process of development. Therefore, identification of the factors that increase participation and are influential on it is tremendous help for collaboration with people in various issues of society.

The theories presented regarding participation and variables introduced in this research have been for design of hypotheses stating correlation between these variables and the level of participation of people. Therefore, hypotheses and fundamental questions were tested with the purpose of evaluation of the presence of correlation between the independent variables and the dependent one which is the level of participation.

Results of inferential statistics show that meaningful correlation exists between independent variables of the research (awareness, feeling of exclusion, level of acceptance of culture, level of belonging felt to the city of residence and the history of presence in the residential area of emigrants living in unofficial sites) and the dependent variable (level of social participation of emigrants residing in the outskirts of the city). These correlations show that with change in each of the independent variables, the dependent variable is affected and changes. Considering this principle, the mentioned variables in this study are all influential variables on the level of social participation of emigrants living in unofficial residential sites of the city of Tabriz.

Various issues and findings in this research have been attained by way of documental and field study regarding participation of residents of unofficial sites in the city of Tabriz which is note worthy:

- In the unofficial residential perimeter of the city of Tabriz, close to 400000 people exist. This population compared to the total population of the city of Tabriz (1700000 individuals) is very significant and shows the extent of unofficial inhabitance of the city of Tabriz and in this regard, this city faces a huge epidemic and the situation and conditions and quality of life in these perimeters are very influential on the issues present in the entire city.

- Unofficial inhabitance in the city of Tabriz in total is divided into 4 geographic areas which are: South of Tabriz, Southwest (Akhmeh Ghieh), Northwest (the big Tabriz Park) and North of Tabriz each of which has its own special characteristics while they also have commonalities as well. 
- Regarding population issues, unofficial inhabitance in the north of Tabriz shows high density of unofficial dwell ship relative to the city of Tabriz. Residents in this region have more than 20 to 30 years of antiquity.

- Regarding level of education and literacy, near $73 \%$ are literate and $27 \%$ illiterate. The level of illiteracy compared to the city with illiteracy of $18 \%$ is higher. This issue shows the bad situation of education or lack of encouragement of individuals to attain scientific learning and knowledge in these regions. The latter itself can be influential on successful or unsuccessful implementation of different plans.

- The level of participation of women in the unofficial residential area is less than that of cities and women participation is more in economic areas for help in making a living for the family and less in cultural and social domains.

- In documental study, the occupation of residents of unofficial sites frequently constitute of repair, labor, rug knitting, agriculture, retail and driver ship and the field study information is also closely similar to this.

- Close to $27 \%$ of women are illiterate. This number is high and is influential on their kind of view point in facing with various social problems.

- In these regions, education level is at a low level. Education level is among indices that evaluates the level of awareness. Here, increased level of education shows increased awareness of individuals and predilection for better understanding of problems and collaboration and participation for solving them.

- The table of distribution of time of residence in this area shows that outskirt regions in Tabriz have antiquity of 60 years and initially they had lower population and gradually this population has increased. In other words, emigration in various forms has occurred and has led to increased population in these regions. Currently, near $85 \%$ of responders have less than 30 years of residency in these regions. This history of presence can lead to feeling of belonging and increase participation. On the other hand, it shows that officials have not been able to contain or resolve the issue which itself increases the feeling of exclusion and inhibits increased resident participation.

- Near $14 \%$ of the women have rug knitting jobs. This occupation is among specialized and traditional occupations in the city of Tabriz and this industry has valuable history in the city.

- The people of the region regarding participation of religious ceremonies mention access as the first factor. The latter shows that if appropriate locations are provided for the purpose of improvement in their quality of life, they will welcome it dearly.

- Close to $60 \%$ of the residents have evaluated the view point of others towards their occupation in terms of value medium and tending towards low and this shows the feeling of exclusion towards their occupation and guild and will decrease participation.

- Near $70 \%$ of the individuals complained of lack of easy access to educational and cultural places. This number is very significant and increases the feeling of exclusion.

- The situation of security in the region by the saying of more than $60 \%$ of the residents is at a low level which itself can also decrease participation.

- Emigrants have chosen residence in these sites not because of advanced facilities in the city, but because of other reasons such as access to better jobs compared to their old situation namely the need for having an occupation.

- The feeling of belonging to the city of Tabriz among residents was evaluated as desired.

\section{Suggestions}

- Considering that one of the principle bases of participation is awareness, with increased awareness in these regions the level and kind of participation of these individuals can be changed. Therefore, increased educational facilities such as schools, universities, training centers and also participation in the literacy movement with attention to the high numbers of illiterates in this region can help realization of this goal.

- Considering the existence of the sense of belonging to the location due to history of presence in these regions, it is possible to influence their participation in social matters by strengthening the sense of belonging by way of enlivening and renovating the regions of interest by the residents and also by building locations that will improve this sense in them.

- Invitation of officials for hearing the issues and problems of the residents of the areas and unofficial sites.

- Prevention of excessive emigration with identification of the source of emigration and resolution of the dispelling factors in those regions. 
- Creation and strengthening common feelings and identification of important commonalities between people living in these residences.

- With reliance on analytic information, unofficial residence is not just a local and regional problem but the issue has to be viewed beyond and more important than it is considered presently. International look towards this problem can help find root solutions.

- Use of capacities and skills of women in advancement of the industry of rug knitting which will both help increase income and also leads to increased bustling of the rug industry will increase participation in social issues.

- Antiquity of unofficial inhabitance shows lack of success of plans. Therefore, it appears that these plans due to their importance need to be viewed at a national level.

- Increased cultural programs in this region due to high welcoming by the residents with the purpose of improvement of cultural problems in the region is recommended.

\section{References}

Arnstein, Social theory and Social Structure : New York ,2000 , P: 210-215.

Bayrou, Allen (1996). Encyclopedia of social sciences (Translation: Saroukhani, Bagher). Tehran: Keyhan.

Daniel Lerner . Class culture and alienation: London : Heath company , 1958 , P : 107-8.

Efati, Mohammad (1992). Evaluation of factors influential on participation of villagers in plans for village development. MS Dissertation, Allameh Tabatabaii University, Tehran, p 38-45.

Ghasemi, Mohammad Ali (2001). Evaluation of socio-economic factors influential on the level of participation of villagers in developmental plans in the central section of the county of Kashan. MS Dissertation, village development, University of Tehran, p18-22.

Lowe et al , political Man : Anchor Book :new York ,1999, 12-17.

linkless. Alienation as a concept in social sciences: Paris: Mouton , the vague,1994,P:5

Mardoukhi, Bayazid (1994). Participation of people in the process of development and a plan for evaluating its level. Journal of Agricultural Economy and Development, Research Center for Planning and Agricultural Economy, Tehran, No6, p 35-40.

Moshirzadeh, Homeira (2002). Theoretical return from social movements. Tehran: Islamic Revolution Research Center.

Peyran, Parviz (1988). Rapid and incongruous city dwellship; slum dwellship in Tehran. Politico-economic Information, Tehran, No 20, p5.

Rafipour, Faramarz (1993). Evaluation of villagers regarding the development crusade. Center for Research and Evaluation of Village Problems, (Research in three provinces of Isfahan, Fars and Khorasan).

Taleb, Mahdi (2000). Twenty five years of research in the villages of Iran/Book of the month, № 38.

Zahed Zahedani, Seyed Saiid (1990). Relationship between individuals and society. Journal of Social and Humanities Sciences, University of Shiraz, Shiraz, Period 5, No2, p29-33. 